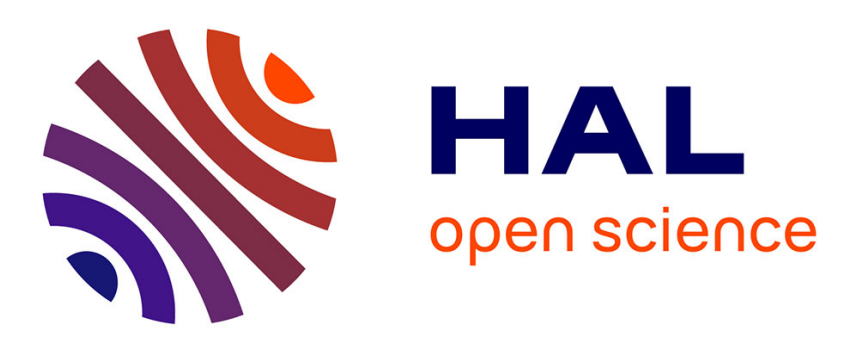

\title{
Drafting during Swimming Improves Efficiency during Subsequent Cycling
}

\author{
Anne Delextrat, Véronique Tricot, Thierry Bernard, Fabrice Vercruyssen, \\ Christophe Hausswirth, Jeanick Brisswalter
}

\section{- To cite this version:}

Anne Delextrat, Véronique Tricot, Thierry Bernard, Fabrice Vercruyssen, Christophe Hausswirth, et al.. Drafting during Swimming Improves Efficiency during Subsequent Cycling. Medicine and Science in Sports and Exercise, 2003, 35 (9), pp.1612-1619. hal-01765340

\section{HAL Id: hal-01765340 https://hal-insep.archives-ouvertes.fr/hal-01765340}

Submitted on 12 Apr 2018

HAL is a multi-disciplinary open access archive for the deposit and dissemination of scientific research documents, whether they are published or not. The documents may come from teaching and research institutions in France or abroad, or from public or private research centers.
L'archive ouverte pluridisciplinaire HAL, est destinée au dépôt et à la diffusion de documents scientifiques de niveau recherche, publiés ou non, émanant des établissements d'enseignement et de recherche français ou étrangers, des laboratoires publics ou privés. 


\title{
Drafting during Swimming Improves Efficiency during Subsequent Cycling
}

\author{
Anne Delextrat ${ }^{1}$, Véronique Tricot ${ }^{1}$, Thierry Bernard ${ }^{1}$, Fabrice Vercruyssen ${ }^{1}$, \\ Christophe Hausswirth ${ }^{2}$, and Jeanick Brisswalter ${ }^{1}$ \\ ${ }^{1}$ University of Toulon-Var, Department of Ergonomics, La Garde cedex, FRANCE \\ ${ }^{2}$ Laboratory of Biomechanics and Physiology, National Institute of Sport and Physical Education, \\ Paris, FRANCE
}

Address for correspondence: Pr. Jeanick Brisswalter, University of Toulon Var, Department of Ergonomics, Avenue de L'Université, BP 132, 8395' La Garde cedex, France; E-mail: brisswalter@univ-tln.fr.

\begin{abstract}
Purpose: The aim of the present study was to investigate the effects of drafting (i.e., swimming directly behind a competitor) while swimming with a wet suit on physiological parameters and cadence during subsequent cycling.

Methods: Eight well-trained male triathletes underwent two submaximal sessions conducted in a counterbalanced order. One of these sessions (SAC) consisted of a 750-m swim, performed at competition pace, followed by a 15 -min ride on a bicycle ergometer at $75 \%$ of maximal aerobic power and at a freely chosen cadence. During the other session (SDC) the subjects swam $750 \mathrm{~m}$ in a drafting position at the same pace as during SAC and then performed the 15-min cycling test at the same intensity as during SAC.
\end{abstract}

Results: The main result indicated that cycling efficiency was significantly improved when the cycling session was preceded by a swimming bout performed in drafting position compared with an isolated swimming bout $(+4.8 \%, P<0.05)$.

Conclusion: These results could be partly explained by the lower relative intensity observed during swimming in the SDC trial when compared with the SAC trial. This study suggests the relative importance of swimming condition and highlights the advantage of drafting during the swimming portion of a sprint triathlon. Key Words: TRIATHLETES, HYDRODYNAMIC DRAG, OXYGEN KINETICS, HEMODYNAMICS, CADENCE

Triathlon, involving successive swimming, cycling and running sessions, has become the most popula multidisciplinary event of the last decade (17). Triathlon competitions are performed over a variety of distance: ranging from the triathlon sprint (750-m swim, $20-\mathrm{km}$ cycle $5-\mathrm{km}$ run) to the Iron man triathlon (3.8-km swim, 180-kir cycle, 42.2-km run). Within this framework, the relative duration of the swimming, cycling, and running section: varies from the shortest to the longest distances from $18 \%$ to $10 \%, 52 \%$ to $56 \%$, and $30 \%$ to $34 \%$, respectively $(12,17)$.

Significant correlations have been reported between cycling or running time and overall triathlon performance, while no significant relationship has been found between swimming time and overall triathlon performance (12). Consequently, most studies have focused or the cycle-to-run transition, whereas research investigating the influence of swimming on subsequent cycling performance is somewhat limited $(11,21,22)$. However despite the lack of experimental studies, recent reviews on 
triathlon determinants highlighted that the metabolic demand induced by swimming could have detrimental effects on subsequent cycling or running adaptations (e.g., 3).

Experimental studies on the effect of prior swimming on subsequent cycling performance have led to contradictory results. Kreider et al. (21) have found that an 800-m swimming bout resulted in a significant decrease in power output (17\%) during a subsequent 75 -min cycling exercise. More recently, Delextrat et al. (11) have observed a significant decrease in cycling efficiency (17.5\%) after a 750-m swim conducted at a sprint triathlon competition pace when compared with an isolated cycling bout. In contrast, Laursen et al. (22) indicated no significant effect of a 3000-m swim performed at a long-distance triathlon competition pace on physiological parameters measured during a subsequent cycling bout. It is therefore suggested that the swimming section could negatively affect the subsequent cycling, especially during sprint triathlon, where the intensity of the swim is higher than during longdistance events.

Within this framework, we showed in a recent study (11) that decreasing the metabolic load during a $750-\mathrm{m}$ swim by using a wet suit resulted in a $11 \%$ decrease in swimming heart rate (HR) values and led to a $12 \%$ improvement in efficiency during a subsequent 10 -min cycling exercise, when compared with swimming without a wet suit. The lower relative intensity when swimming with a wet suit is classically explained by a decrease in hydrodynamic drag. This decrease in hydrodynamic drag results from an increased buoyancy that allows the subjects to adopt a more horizontal position, thus reducing their frontal area (7).

During swimming, hydrodynamic drag could also be reduced when swimming in a drafting position (i.e., swimming directly behind another competitor). The effects of drafting during short swimming bouts have been widely studied in the recent literature $(2,8,10,24)$. The main factor of decreased body drag with drafting seems to be the depression made in the water by the lead swimmer (3). This low pressure behind the lead swimmer decreases the pressure gradient from the front to the back of the following swimmer, hence facilitating his displacement through the water (8). Within this framework, significant decreases in passive drag (i.e., drag forces exerted on subjects passively towed through the water in prone position (8)) from $10 \%$ to $26 \%$ have been reported in a drafting position compared with isolated conditions (for review, (3)). Moreover, swimming in drafting position is associated with significant reductions in oxygen uptake (10\%), HR (6.2\%), and blood lactate concentration (11-31\%) $(2,8)$.

During a multidisciplinary event, such as triathlon, the effect of drafting on subsequent performance has been studied only during the cycling leg. Hausswirth et al. (17) showed that drafting during the cycle portion of a sprint triathlon led to a significant decrease in cycling energy expenditure (14\%) compared with an individual effort, leading to a $4.1 \%$ improvement in performance during the subsequent $5-\mathrm{km}$ run. To the best of our knowledge, no similar study has been conducted during a swim-bike trial, in order to evaluate the effects of drafting during swimming on subsequent cycling performance

The objective of the present study was therefore to investigate the effects of drafting during swimming on energy expenditure in the context of a swim-bike trial. We hypothesized that swimming in drafting position would be associated with a lower metabolic load during swimming and would reduce energy expenditure during subsequent cycling.

\section{MATERIALS AND METHODS Subjects}

Eight male triathletes competing at interregional or national level (age: $26 \pm 6 \mathrm{yr}$, height: $183 \pm 7 \mathrm{~cm}$, weight: $74 \pm 7 \mathrm{~kg}$, body fat: $133 \%$ ) participated to this study. They were all familiarized with laboratory testing. Average training distances per week were $6.6 \mathrm{~km}$ in swimming, $59 \mathrm{~km}$ in cycling, and $34 \mathrm{~km}$ in running, which represented $150 \mathrm{~min}, 135 \mathrm{~min}$, and $169 \mathrm{~min}$ for these three disciplines, respectively. This training program included only one cross-training session (cycle-to-run) per week. The low distance covered by the triathletes during training, especially in cycling could be partly explained because the experiment was undertaken in winter, when triathletes usually decrease their 
training load in the three disciplines. Written consent was given by all the subjects before ail testing and the ethics committee for the protection of individuals gave their approval of the project before its initiation (Saint-Germain-en-Laye, France).

\section{Protocol}

Maximal oxygen uptake $\left(\mathrm{V0}_{2, \%}\right.$, ) and maximal aerobic power (MAP) determinations. The first test was a laboratory incremental test on a cycle ergometer to determine $\mathrm{VO}_{2}$. and MAP. After a 6-min warm-up at $150 \mathrm{~W}$, the power output was increased by $25 \mathrm{~W}$ every 2 min until volitional exhaustion. The criteria used for the determination of $\mathrm{VO}_{2}$. were: a plateau in $\mathrm{VO}_{2}$ despite the increase in power output, a HR over $90 \%$ of the predicted maximal HR, and a respiratory exchange ratio (RER) over 1.15 (19). Because $\mathrm{VO}_{2} \max$ was used as a simple descriptive characteristic of the population for the present study and was sot a primary dependent variable, the attainment of two out of three criteria was considered sufficient (19). The ventilatory threshold (VT) was calculated using the criteria of an increase in $\mathrm{VE} / \mathrm{VCO}_{2}$ with no concomitant increase of $\mathrm{VE} / \mathrm{VCO}_{2}(28)$.

Submaximal sessions. After this first test, each triathlete underwent three submaximal sessions separated by at least $48 \mathrm{~h}$. The experimental protocol is described in Figure 1. All swim tests took place in the outdoor Olympic swimming pool of Hyères (Var, France) and were performed with a neoprene wet suit (integral wet suit Aquaman ${ }^{\circledR}$, Pulsar 2000, thickness: shoulders: $1.5 \mathrm{~mm}$, trunk: $4.5 \mathrm{~mm}$, legs: $1.5 \mathrm{~mm}$, arms: $1.5 \mathrm{~mm}$ ) The cycling tests were conducted adjacent to the swimming pool in order to standardize the duration of the swim-to-cycle transition $(3 \mathrm{~min})$. The first test was always a $750-\mathrm{m}$ swim performed alone at a sprint triathlon competition pace (SA trial). It was used to determine the swimming intensity for each subject. The two other tests, presented in a counterbalanced order, comprised one swim-to-cycle transition performed alone (SAC trial) and one swim-to-cycle transition with a swimming bout performed in drafting position (SDC trial).

The SAC trial consisted of a 750-m swim at the pace adopted during SA, followed by a 15-min ride on the bicycle ergometer at $75 \%$ of MAP and at a freely chosen cadence (FCC). This intensity was chosen to be comparable with the cycling competition pace during a sprint triathlon reported in subjects of the same level by previous studies (e.g., 17). Moreover, it was similar to those used in recent works studying the cycle-to-run transition in trained triathletes (e.g., 27). During the SDC trial, the subjects swam $750 \mathrm{~m}$ in drafting position (i.e., swimming directly behind a competitive swimmer in the same lane) at the pace adopted during SA. They then performed the 15-min ride at the same intensity as during SAC. The lead swimmer, who was used for ail the triathletes, was a highly trained swimmer competing at international level. To reproduce the swimming pace adopted during SA, the lead swimmer was informed of his performance every $50 \mathrm{~m}$ via visual feedback.

\section{Measured Parameters}

Swimming trials. During each swimming trial, the time to cover each $50 \mathrm{~m}$ and overall time were recorded. Subjects were instructed to keep the velocity as constant as possible. Stroke frequency (SF), expressed as the number of complete arm cycles per minute, was measured for each $50 \mathrm{~m}$ on a $20-\mathrm{m}$ zone situated in the middle of the pool. The stroke length (SL) was calculated by dividing the mean velocity of each 20-m swim by the mean SF of each $20-\mathrm{m}$ swim.

Immediately after each trial, the triathletes were asked to report their perceived exertion (RPE) using the 15-graded Borg scale (from 6 to 20 (5)).

Blood sampling. Capillary blood samples were collected from subjects' earlobes at the following times: 1 and 3 min after swimming (L1, L2), and at the third and 15th minutes of cycling (L3, L4). Blood lactate concentration (LA, mmol.L ${ }^{-1}$ ) was then measured by the lactate Pro ${ }^{\mathrm{TM}}$ LT-1710 portable lactate analyzer (Arkray, KDK, Japan). The highest of the two postswim (L1, L2) concentrations was considered as the postswim lactate value, because the time delay for lactate to diffuse from the muscles to the blood during the recovery from a swimming exercise has not been precisely established (23). 
Measurement of respiratory gas exchange. During the cycling trials, oxygen uptake $\left(\mathrm{VO}_{2}\right), \mathrm{HR}$, and respiratory parameters (expiratory flow: VE; respiratory frequency: RF) were monitored breath-bybreath and recorded by the Cosmed $\mathrm{K} 4 \mathrm{~b}^{2}$ telemetric system (Rome, Italy).

HR was continuously monitored during swimming and cycling using a cardiofrequency meter (Polar Vantage, Kempele, Finland).

Physiological solicitation of cycling was assessed using oxygen kinetics analysis (e.g., 29); energy expenditure was analyzed by gross efficiency calculation (9).

Curve fitting. Oxygen kinetics were modeled according to the method used by Barstow et al. (1). Breath-by-breath $\mathrm{VO}_{2}$ data were smoothed in order to eliminate the outlying breaths (defined as those that were lying outside two standard deviations of the local mean). For each trial (SDC and SAC), the time course of the $\mathrm{VO}_{2}$ response after the onset of the cycling exercise was described by two different exponential models that were fit to the data with the use of nonlinear regression techniques in which minimizing the sum of squared error was the criterion for convergence.

The first mathematical model was a mono-component exponential model:

$$
\dot{\mathrm{V}} \mathrm{O}_{2}(\mathrm{t})=\dot{\mathrm{V}} \mathrm{O}_{2}(\mathrm{~b})+\mathrm{A} \cdot\left(1-\mathrm{e}^{-(\mathrm{t}-\mathrm{TD}) / \tau}\right)
$$

The second mathematical model was a two-component exponential model:

$$
\dot{\mathrm{V}} \mathrm{O}_{2}(\mathrm{t})=\dot{\mathrm{V}} \mathrm{O}_{2}(\mathrm{~b})+\mathrm{A}_{1} \cdot\left(1-\mathrm{e}^{-\left(\mathrm{t}-\mathrm{TD}_{1}\right) / \tau_{1}}\right)+\mathrm{A}_{2} \cdot\left(1-\mathrm{e}^{-\left(\mathrm{t}-\mathrm{TD}_{2}\right) / \tau_{2}}\right)
$$

The use of one of these models depends on the relative exercise intensity (29). The mono-component exponential model characterizes the $\mathrm{VO}_{2}$ response during an exercise of moderate intensity (i.e., below the lactate threshold). After a time delay corresponding to the transit time of blood flow from the exercising muscle to the lung (TD), $\mathrm{VO}_{2}$ increases exponentially toward a steady state level. The $\mathrm{VO}_{2}$ response is characterized by an asymptotic amplitude (A) and a time constant (T) defined as the time to reach $63 \%$ of the difference from final plateau value and baseline $\left(\mathrm{VO}_{2}(\mathrm{~b})\right.$, corresponding to the value recorded on the bicycle before the onset of cycling). At higher intensities, the $\mathrm{VO}_{2}$ response is modeled by a two-component exponential function. The first exponential term describes the rapid rise in $\mathrm{VO}_{2}$ previously observed (the parameters $\mathrm{TD}_{1}, \mathrm{~A}_{1}$, and $\tau_{1}$ are identical to $\mathrm{TD}, \mathrm{A}$, and $\mathrm{T}$ of the monocomponent exponential model), whereas the second exponential term characterizes the slower rise in $\mathrm{VO}_{2}$ termed " $\mathrm{VO}_{2}$ slow component" that is superimposed on the rapid phase of oxygen uptake kinetics. The parameters $\mathrm{TD}_{2}, \mathrm{~A} 2$, and $\tau_{2}$ represent, respectively, the time delay, asymptotic amplitude, and time constant for this exponential term. The computation of best-fit parameters was chosen by a computer program (SigmaPlot 7.0) so as to minimize the sum of the squared differences between the fitted function and the observed response.

Determination of cycling gross efficiency. Cycling gross efficiency (GE, \%) was calculated as the ratio of work accomplished per minute $\left(\mathrm{kJ} \bullet \mathrm{min}^{-}{ }^{1}\right)$ to metabolic energy expended per minute $\left(\mathrm{kJ} \bullet \mathrm{min}^{-1}{ }^{1}\right.$. Because relative intensity of the cycling bouts could be superior to VT, the aerobic contribution to metabolic energy was calculated from the energy equivalents for oxygen (according to respiratory exchange ratio value) and a possible anaerobic contribution was estimated using blood lactate increase with time (à lactate: $63 \mathrm{~J}-\mathrm{kg}^{-1} \cdot \mathrm{mM}^{-1} ; 13$ ). For this calculation, $\mathrm{VO}_{2}$ and lactate increase was estimated from the difference between the 15th and the third minutes.

Pedal rate. All the cycling tests were performed on an electromagnetically braked cycle ergometer (SRM Jülich, Welldorf, Germany) The cycle ergometer was equipped with the triathletes' own pedals, 
and the handlebars and racing seat were fully adjustable both vertically and horizontally to reproduce conditions known from their own bicycles. The SRM system can maintain a constant power output independent of the pedal rate spontaneously adopted by the subjects.

\section{Statistical Analysis}

All the results were expressed as mean and standard deviation (mean SD). Differences between the two conditions (swimming alone or in drafting position) in physiological and biomechanical parameters were analyzed using a Student t-test for paired samples. The level of confidence was set at $P<0.05$.

\section{RESULTS}

\section{Maximal Test}

The subjects' physiological characteristics recorded during the incremental cycling test are presented in Table $1 . \mathrm{VO}_{2 \mathrm{~m}} \mathrm{a}_{\mathrm{x}}$ values were close to those previously obtained for triathletes of the same level $(6,27)$. From VT values, it could be observed that the cycling bouts were performed at an intensity close to VT $+2 \%$.

\section{Swimming Trials}

Performance. No significant difference in performance was observed between the two swimming trials (respectively for SAC and SDC: $638 \pm 38 \mathrm{~s}$ and $637 \pm 39 \mathrm{~s}, P>0.05$ ). The two 750-m swims were therefore performed at a mean velocity of $1.18 \mathrm{~m}-\mathrm{s}{ }^{-1}$. In addition, the stroke characteristics (SR and SL) were not significantly different between SAC and SDC trials (mean SR: $33.2 \pm 4.5$ cycles $^{\bullet} \mathrm{min}^{-}$ ${ }^{1}$ vs $33.1 \pm 5.1$ cycles. $\min ^{-1}$, respectively, for SAC and SDC, $P>0.05$; mean SL: $2.13 \pm 0.29 \mathrm{rn}^{\bullet}$ cycle $^{-1}$ vs $2.15 \pm 0.30 \mathrm{~m}^{\bullet} \mathrm{cycle}^{-1}$, respectively, for SAC and SDC, $P>0.05$ ). During the SDC trial, the mean distance between the subjects (draftees) and the lead swimmer did not exceed $1 \mathrm{~m}$.

Physiological parameters and RPE. The HR values recorded during the last $5 \mathrm{~min}$ of swimming are presented in Figure 2. The main result shows that swimming in drafting position resulted in a significant mean decrease of $7 \%$ in HR values during the last 4 min of swimming in comparison with the isolated swimming bout $\left(160 \pm 15\right.$ beats. $\mathrm{min}^{-1}$ vs $172 \pm 18$ beats $\bullet \mathrm{min}^{-1}$, respectively, for SDC and SAC trials, Fig. 2, $P<0.05)$. Furthermore, postswim lactate values were significantly lower $(29.3 \%)$ after the SDC session when compared with the SAC session $\left(5.3 \pm 2.1 \mathrm{mmol}-\mathrm{L}^{-1}\right.$ vs $7.5 \pm 2.4 \mathrm{mmol} \cdot \mathrm{L}^{-}$ ${ }^{1}$, respectively, for SDC and SAC trials, $P<0.05$ ).

Finally, RPE values recorded immediately after swimming indicated that the subjects' perception of effort was significantly lower in the SDC trial than in the SAC trial $(13 \pm 2$ vs $15 \pm 1$, corresponding to "rather laborious" versus "laborious" respectively for SDC and SAC trials, $P<0.05$ ).

\section{Cycling trials}

$\mathbf{V O}_{2}$ kinetics. All $\mathrm{VO}_{2}$ responses were best fitted by a mono-component exponential model, except the ' $\mathrm{O}_{2}$ responses of one subject during the SAC trial that were best described by a two-component exponential function. The occurrence of a slow component in this latter case is representative of a heavy-intensity exercise whereas the other subjects have exercised in a moderate-intensity domain (29). Therefore, the parameters of the model for this subject are different (two-component exponential model vs mono-component exponential model) and could not be included in the same analysis. Figure 3 shows the breath-by-breath $\mathrm{VO}_{2}$ responses during SAC and SDC trials for a representative subject (responses best fitted by a mono-component exponential model, Fig. 3A) as well as the breath-bybreath $\downarrow / 0_{2}$ responses for the subject eliminated (responses best fitted by a two-component exponential model, Fig. 3B). Statistical analysis shows that baseline $\mathrm{VO}_{2}$ values were sot significantly different between SAC and SDC trials $(P>0.05)$. However, we have observed that during the SAC trial, higher $\mathrm{VO}_{2}$ values at the steady state level were attained more quickly than during the SDC trial (time constant values for SAC and SDC trials were, respectively, $17.1 \pm 7.8 \mathrm{~s}$ vs $23.6 \pm 10.1 \mathrm{~s}$ for $\mathrm{VO}_{2}$ 
kinetics, $P<0.05)$.

Mean physiological parameters and RPE. The influence of drafting, during prior swimming, on the mean physiological values measured during subsequent cycling is presented in Table 2 . The statistical analysis shows that cycling efficiency was significantly higher in the SDC trial (4.8\%) in comparison with the SAC trial $(P<0.05)$. The V02. HR and lactate values measured during cycling were significant higher when previous swimming was performed alone compared with the drafting condition (Table 2, $P<0.05$ ). However, no significant increase in blood lactate concentration with time was observed, indicating the main contribution of aerobic metabolism (13). Therefore, the decrease in gross efficiency during the SAC trial is related to higher $\mathrm{VO}_{2}$ values. Furthermore, the subjects' RPE was significantly lower in the SDC trial compared to the SAC trial $(15 \pm 2$ vs $17 \pm 2$, corresponding to "laborious" vs "very laborious," $P<0.05$ ).

Pedal rate. The statistical analysis indicated a significant difference in pedal rate measured during cycling between the two conditions. A significantly lower pedal rate (5.6\%) was observed in the SDC trial in comparison with the SAC trial (Table 2, $P<0.05$ ).

\section{DISCUSSION}

The main result of the present study indicated a significant effect of swimming metabolic load on oxygen kinetics and efficiency during subsequent cycling at competition pace. Within this framework, a prior 750-m swim performed clone resulted in faster oxygen kinetics and a significantly higher global energy expenditure during subsequent cycling, in comparison with an identical swimming bout performed in a drafting position $(P<0.05)$.

Drafting during swimming and swimming metabolic load. The effects of drafting on energy expenditure during short- or long-distance events have been investigated over a variety of physical activities. Drafting has been shown to significantly reduce the metabolic load during swimming (2), cycling (17), cross-country skiing (25), and speed skating (26). The lower energy cost observed in a drafting position is classically attributed to a decrease in aerodynamic or hydrodynamic drag $(2,17)$. In this context, Bassett et al. (2) have suggested that the decrease in drag associated with drafting was lower in swimming in comparison with terrestrial activities. This is because of the characteristics of swimming such as the relatively low velocity, the prone position, and the turbulence owing to the kicks of the lead swimmer. Decreases in passive hydrodynamic drag in drafting position from $10 \%$ to $26 \%$ have been reported in the literature $(8,24)$. It should be noted that the active drag experienced by a subject while swimming is approximately 1.5-2 times greater than passive drag (14).

In this study, the HR values recorded during the two swimming bouts (Fig. 2) shows mean HR values corresponding respectively for SDC and SAC trials to $84.2 \%$ and $90.5 \%$ of $\mathrm{HR}_{\max }$ measured during cycling. Consequently, drafting involved a significant $7 \%$ decrease in HR during a 750 -m swim $(P<$ $0.05)$. Furthermore, the SDC trial was characterized by significant reductions in postswim lactate values $(29.3 \%)$ and RPE values (20\%), in comparison with the SAC trial.

The main factor classically evoked in the literature to explain the lower swimming energy cost in drafting position is the reduction of hydrodynamic drag owing to the body displacement of the leading swimmer. The extent to which hydrodynamic drag could be reduced in a drafting position depends on several factors, such as swimming velocity and the distance separating the draftee and the lead swimmer. Concerning the distance between the swimmers, there seems to be a compromise between the positive effect of the hydrodynamic wake created by the lead swimmer and the negative effect of the turbulence generated by his kicks $(2,8,24)$. However, during triathlon, the draftee could follow the lead swimmer quite closely because triathletes usually adopt a two-beat kick that does not generate excessive turbulence.

The effects of drafting during short-distance swimming bouts have been well documented in the literature $(2,8,10)$. However, during these experiments, the race conducted in drafting position was performed either at the same relative velocity as the isolated condition (2), or the subjects were asked 
to swim as fast as possible during the second half of the race $(8,10)$. Using a protocol comparable to the present study, Bassett et al. (2) have observed during a 549-m swim (600 yards) performed at $1.20 \mathrm{~m} \bullet \mathrm{s}-$ ${ }^{1}\left(1.18 \mathrm{~m} \cdot \mathrm{s}^{-1}\right.$ in the present study) significantly lower HR $(6.2 \%)$, lactate $(31 \%)$, and RPE values $(21 \%)$ when the swimming bout was performed in a drafting position $(P<0.05)$, compared with an isolated effort. These results are in agreement with this previous study. One interesting result of this study is that the significant effect of drafting previously reported in the literature was observed even though our subjects were wearing a wet suit. It has been reported that the use of wet suit induced significant decreases in energy cost (from $7 \%$ to $22 \%$ ) and active drag (from $12 \%$ to $16 \%$ ) among different speeds (for review, (7)). It could be concluded that during triathlon events, where subjects are wearing wet suits, drafting could further increase the reduction in metabolic load during swimming.

Drafting during swimming and cycling exercise. In the present study, the decrease in metabolic load associated with swimming in a drafting position involved two main modifications in physiological parameters during subsequent cycling. First, $\mathrm{VO}_{2}$ kinetics, at the onset of cycling, were significantly slowed when the prior swimming bout was performed in a drafting position (slower time constant, $\tau \mathrm{V} 02)$ compared with swimming alone $(P<0.05)$. Second, a significantly higher cycling efficiency, measured at steady state level, was observed in the SDC trial versus the SAC trial $(+4.8 \%, P<0.05)$.

The modification in $\mathrm{VO}_{2}$ kinetics observed in the present study is in accordance with previous results reported in the literature. During the last decade, several investigations have analyzed the influence of previous exercise metabolic load on the rate of $\mathrm{VO}_{2}$ increase at the onset of subsequent exercise. Gerbino et al. (15) have found that $\mathrm{VO}_{2}$ kinetics during a high-intensity cycling exercise (i.e., greater than the lactate threshold) was significantly increased by a prior high-intensity cycling bout, whereas no effect was reported after a prior low-intensity exercise (i.e., lower than the lactate threshold). In addition, Bohnert et al. (4) have observed an acceleration of $\mathrm{VO}_{2}$ kinetics when a cycling trial was preceded by a high-intensity arm-cranking exercise.

Many studies have been conducted in order to identify the mechanisms underlying the rate of $\mathrm{VO}_{2}$ increase at the onset of exercise (e.g., 29). Although these mechanisms are not clearly established, two major hypotheses are reported in the literature. Some authors suggest that $\mathrm{VO}_{2}$ kinetics are limited by the rate of oxygen supply to the active muscle mass, whereas others report that the capacity of muscle utilization is the most important determinant of $\mathrm{VO}_{2}$ responses at the onset of exercise (29). Concerning the hypothesis of oxygen transport limitation, Hughson et al. (20) investigated the influence of an improved perfusion of active muscle mass during cycling on the rate of $\mathrm{VO}_{2}$ increases at the onset of exercise. These authors found that $\mathrm{VO}_{2}$ kinetics at the onset of exercise were significantly faster when the perfusion of active muscle mass was augmented. In our study, several factors could be evoked to increase perfusion in the muscles of the lower limbs during cycling, such as previous metabolic load and pedal rate.

Gerbino et al. (15) suggested that the faster $\mathrm{VO}_{2}$ kinetics observed during the second bout of two repeated high-intensity cycling exercises could be accounted for by the residual metabolic acidemia from previous high-intensity exercise, involving a vasodilatation and thus an enhancing blood flow to the active muscle mass at the start of subsequent cycling bout. In favor of this hypothesis, a higher metabolic acidemia was observed in the present study immediately after the swimming stage of the SAC trial in comparison with the SDC trial (postswim lactate values: $7.5 \pm 2.4$ mmol. $^{-1}$ vs $5.3 \pm 2.1$ $\mathrm{mmol} \cdot \mathrm{L}^{-1}$ for SAC and SDC trials, respectively, $P<0.05$ ). Therefore, we suggest that the higher contribution of anaerobic metabolism to energy expenditure when swimming alone has involved a better perfusion of active muscular mass at the start of subsequent cycling exercise.

However, in this study, subjects adopted a higher pedal rate after the swimming bout performed alone. There is little information on the effects of pedal rate manipulation on cardiovascular adjustments during cycling. However, Gotshall et al. (16) have indicated an enhanced muscle blood flow with increasing cadences from 70 to $110 \mathrm{rpm}$. Indeed, the frequency of contraction and relaxation of the muscles of the lower limbs increases throughout high cadences, improving venous return and therefore heart filling. As a consequence, the skeletal muscle pump is progressively more effective, resulting in an over perfusion of the active muscle mass (16). According to this hypothesis, the significantly higher 
pedal rate reported in the present study in the SAC trial in comparison with the SDC trial (Table 2, $P<$ 0.05 ) could have involved an increased blood flow to the muscles of the lower limbs. Therefore, both the higher contribution of anaerobic metabolism to energy expenditure during prior swimming and the higher pedal rates adopted during subsequent cycling in the SAC trial could account for the faster $\mathrm{VO}_{2}$ kinetics observed at the onset of cycling in this trial in comparison with the SDC trial.

The second principal result of the present study indicated a significantly higher cycling efficiency during the SDC trial in comparison with the SAC trial (Table 2, $P<0.05$ ). To the best of our knowledge, the effects of drafting during swimming on subsequent cycling adaptation have never been investigated. However, these results were similar to another study from our laboratory showing that wearing a neoprene wet suit reduced the metabolic load at the end of swimming and led to a $12 \%$ increase in subsequent cycling efficiency (11). In our study, subjects were wearing a wet suit, and our results indicated that drafting could lead to a further improvement of cycling efficiency.

In the context of multidisciplinary events, the effect of drafting on subsequent performance has been mainly studied during the cycle-to-run portion of a simulated sprint triathlon $(17,18)$. For example, Hausswirth et al. (17) reported that the significant reductions in $\mathrm{VO}_{2} \mathrm{VE}, \mathrm{HR}$, and blood lactate concentration during the cycle stage of a simulated sprint triathlon $(0.75-\mathrm{km}$ swim, $20-\mathrm{km}$ cycle, $5-\mathrm{km}$ run), observed when cycling was performed in drafting position in comparison with an isolated cycling stage, were related to significant increases in subsequent running velocity (4.1\%). More recently, Hausswirth et al. (18) observed that drafting continuously behind a leader during the 20-km stage of a sprint triathlon resulted in a significantly lower cycling metabolic cost, in comparison with alternating drafting and leading every $500 \mathrm{~m}$ at the same pace. This lower metabolic cost led to a $4.2 \%$ improvement in velocity during a subsequent $5-\mathrm{km}$ run (18). These authors suggested that during the drafting conditions (drafting position vs isolated cycling, or continuous vs alternate drafting), the decrease in energy cost of cycling is the main factor of running performance improvement. In the present study, the cycling bouts were conducted at constant speed. Therefore, no improvement in performance (i.e., velocity) could be observed. However, we recorded a $4.8 \%$ increase in cycling efficiency after a swimming bout performed in drafting position compared with an isolated swimming bout. This improvement in cycling efficiency could be mainly accounted for by the lower swimming relative intensity involving a lower state of fatigue in the muscles of the lower limbs at the beginning of subsequent cycling. Consequently, in long-distance events such as triathlon, where performance depends on the capacity to spend the lowest amount of metabolic energy during the whole race $(17,18)$, we suggest that the increase in cycling efficiency could lead to an improvement in performance. However, further studies are needed to investigate the effects of this improved cycling efficiency on running and total triathlon performance.

However, it should be noted that the possibility for athletes and coaches to put the results of the present study into practice could be limited by the Jack of cycling training of our subjects and by the difference between the intensity and duration of the cycling trials in this study and the metabolic load encountered during a sprint triathlon (17). Because cycling experience could lead to a lower variability in energy cost of locomotion, more training in cycling would be associated with a lower benefit of drafting. Furthermore, even if a measure of actual cycling performance improvements after drafting (such as time or power output) would have been more applicable to competition, the constant power output set in this study allowed the quantification of the modifications in energy expenditure during cycling, which is a main determinant of triathlon performance $(17,18)$. Further studies are necessary to validate the effects observed in this study during a real triathlon event.

In conclusion, the results of the present study show that the metabolic load during swimming could have a significant effect on subsequent cycling performance during a sprint triathlon. In particular, a decrease in swimming relative intensity could lead to a significantly higher efficiency during subsequent cycling. These findings highlight that swimming behind another athlete is beneficial during triathlon events. Within this framework, further studies could include a running session to investigate more precisely the effects of drafting during the swimming bout of a sprint triathlon on total triathlon performance. 
The authors acknowledge all the triathletes who took part to the experiment for their high cooperation and motivation. We are also grateful to Rob Suriano for his assistance with the language.

\section{REFERENCES}

BARSTOW, T. J., A. M. JONES, P. H. NGUYEN, and R. CASABURI. Influence of muscle fiber type and pedal frequency on oxygen uptake kinetics of heavy exercise. J. Appl. Physiol. 81:1642-1650, 1996.

2. BASSETT, D. R., J. FLOHR, W. J. DUEY, E. T. HOWLEY, and R. N. PEIN. Metabolic responses to drafting during front crawl swimming. Med. Sci. Sports Exerc. 23:744-747, 1991.

3. BENTLEY, D. J., G. P. MILLET, V. E. VLECK, and L. R. MCNAUGHTON. Specific aspects of contemporary triathlon. Sports Med. 32:1-15, 2002.

4. BOHNERT, B., S. A. WARD, and B. J. WHIPP. Effects of prior arm exercise on pulmonary gas exchange kinetics during high intensity leg exercise in humans. Exp. Physiol. 83:557-570, 1998.

5. BORG, G. A. V. Perceived exertion as an indicator of somatic stress. Scand. J. Rehabil. Med. 2:9298, 1970.

6. BRISSWALTER, J., C. HAUSSWIRTH, D. SMITH, F. VERCRUYSSEN, and J. M. VALLIER. Energetically optimal cadence vs. freely-chosen cadence during cycling: effect of exercise duration. Int J. Sports Med. 21:60-64, 2000.

7. CHATARD, J. C., and G. MILLET. Effects of wetsuit use in swimming events. Sports Med. 22:70-75, 1996.

8. CHATARD, J. C., D. CHOllet, and G. Millet. Performance and drag during drafting swimming in highly trained triathletes. Med. Sci. Sports Exerc. 30:1276-1280, 1998.

9. CHAVARREN, J., and J. A. L. CALBET. Cycling efficiency and pedalling frequency in road cyclists. Eur. J. Appl. Physiol. 80:555-563, 1999.

10. CHOLLET, D., O. HUE, F. AUCLAIR, G. MILLET, and J. C. CHATARD. The effects of drafting on stroking variations during swimming in elite male triathletes. Eur. J. Appl. Physiol. 82: 413-417, 2000 .

11. DELEXTRAT, A., T. BERNARD, C. HAUSSWIRTH, F. VERCRUYSSEN, and J. BRISSWALTER. Effect of wet suit use on energy expenditure during a swim-to-cycle transition. Can. J. Appl. Physiol. (in press).

12. DENGEL, D. R., M. G. FLYNN, D. L. COSTILL, and J. P. KIRWAN. Determinants of success during triathlon competition. Res. Q. Exerc. Sport 60:234-238, 1989.

13. DI PRAMPERO, P. E. Energetics of muscular exercise. Rev. Physiol. Biochem. Pharmacol. 89:143-223, 1981.

14. DI PRAMPERO, P. E., D. R. PENDERGAST, D. W. WILSON, and D. W. RENNIE. Energetics of swimming in man. J. Appl. Physiol. 37:1-5, 1974.

15. GERBINO, A., S. A. WARD, and B. J. WHIPP. Effects of prior exercise on pulmonary gasexchange kinetics during high-intensity exercise in humans. J. Appl. Physiol. 80:99-107, 1996.

16. GOTShall, R. W., T. A. BAUER, and S. L. FAHMER. Cycling cadence alters exercise hemodynamics. Int. J. Sports Med. 17:17-21, 1996.

17. HAUSSWIRTH, C., D. LEHÉNAFF, P. DRÉANO, and K. SAVONEN. Effects of cycling alone or in a sheltered position on subsequent running performance during a triathlon. Med. Sci. Sports Exerc. 31:599 - 604, 1999.

18. HAUSSWIRTH, C., J. M. VALLIER, D. LEHÉNAFF, et al. Effect of two drafting modalities in cycling on running performance. Med. Sci. Sports Exerc. 33:1-8, 2000.

19. HOWLEY, E. T., D. R. BASSET, and H. G. WELCH. Criteria for maximal oxygen uptake: review and commentary. Med. Sci. Sports Exerc. 27:1292-1301, 1995.

20. HUGHSON, R. L., H. C. XING, and C. BORKHOFF. Kinetics of ventilation and gas exchange during supin and upright cycle exercise. Eur. J. Appl. Physiol. 63:300-307, 1991.

21. KREIDER, R. B., T. BOONE, W. R. THOMPSON, S. BURKES, and C. W. CORTES. Cardiovascular and thermal responses of triathlon performance. Med. Sci. Sports Exerc. 20:385-390, 
1988.

22. LAURSEN, P. B., E. C. RHODES, and R. H. LANGILL. The effects of 3000-m swimming on subsequent 3-h cycling performance: implications for ultraendurance triathletes. Eur. J. Appl. Physiol. 83:28-33, 2000.

23. LEPERS, R., A. X. BIGARD, C. HAUSSWIRTH, and C. Y. GUEZENNEC. Swimming-cycling transition modelisation of a triathlon in laboratory. Influence on lactate kinetics. Sci. Sports 10:131139, 1995.

24. MILLET, G., D. CHOLLET, and J. C. CHATARD. Effects of drafting behind a two- or a six-beat kick swimmer in elite female triathletes. Eur. J. Appl. Physiol. 82:465-471, 2000.

25. SPRING, E., S. SAVOLAINEN, J. ERKKILÄ, T. HäMÄLÄINEN, and P. PIHKALA. Drag area of a cross-country skier. Int. J. Sport Biomech. 4:103.113, 1988.

26. VAN INGEN SCHENAU, G. J. The influence of air friction in speed skating. J. Biomech. 15:449458, 1982.

27. VERCRUYSSEN, F., J. BRISSWALTER, C. HAUSSWIRTH, T. BERNARD, O. BERNARD, and J. M. VALLIER. Influence of cycling cadence on subsequent running performance in triathletes. Med. Sci. Sports. Exerc. 34:530-536, 2002.

28. WASSERMAN, K., B. J. WHIPP, S. N. KOYAL, and W. L. BEAVER. Anaerobic threshold and respiratory gas exchange during exercise. J. Appl. Physiol. 35:236-243, 1973.

29. Xu, F., and E. C. RHODES. Oxygen uptake kinetics during exercise. Sports Med. 27:313-327, 1999.

\section{FIGURES and TABLES}

FIGURE 1-Experimental protocol. L: blood sampling, K4 $\mathrm{b}^{2}$ : installation of the Cosmed K4 $\mathrm{b}^{2}$ analyzer.
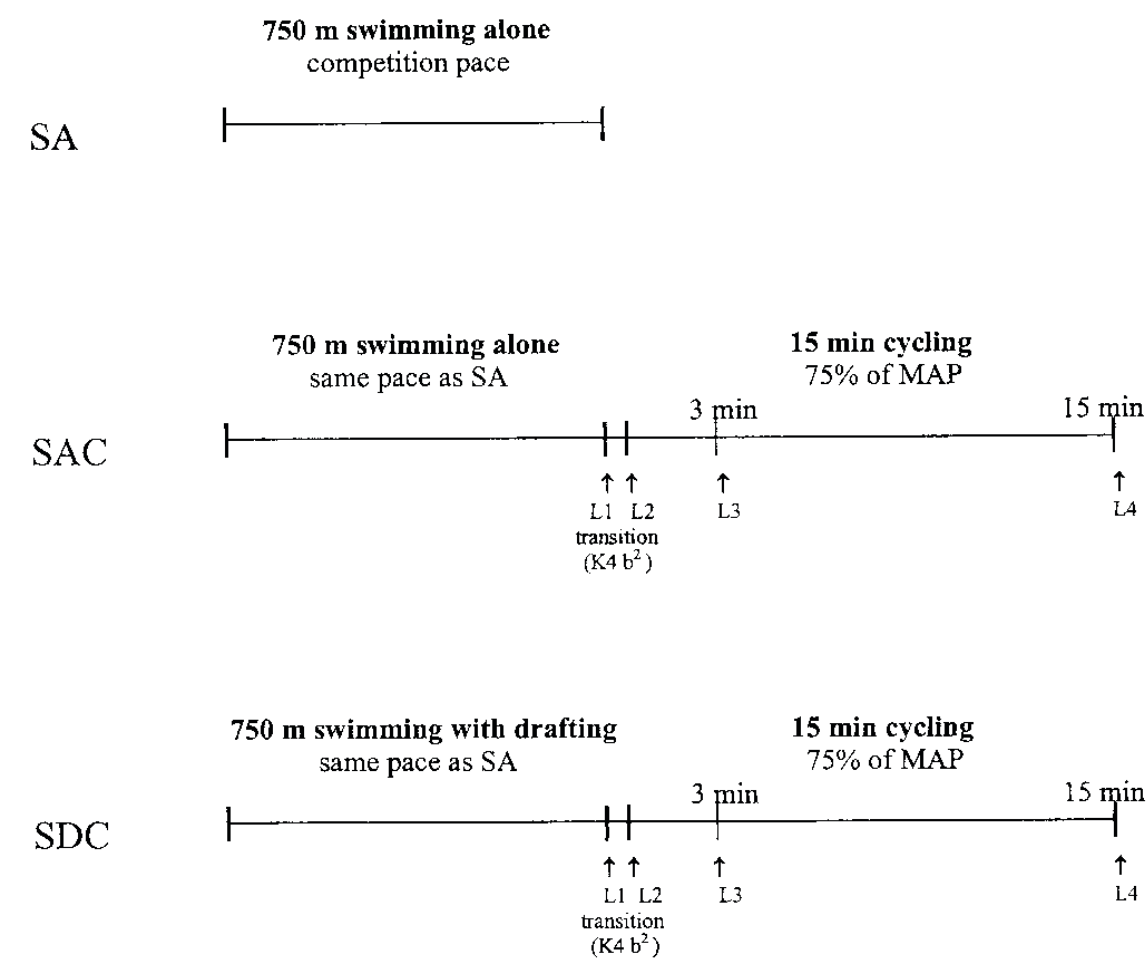
FIGURE 2-Changes in HR values during the fast 5 min of the two swimming trials (SAC and SDC). *Significant difference between SDC and SAC trials, $P<0.05$.

Heart rate (beats. $\min ^{-1}$ )

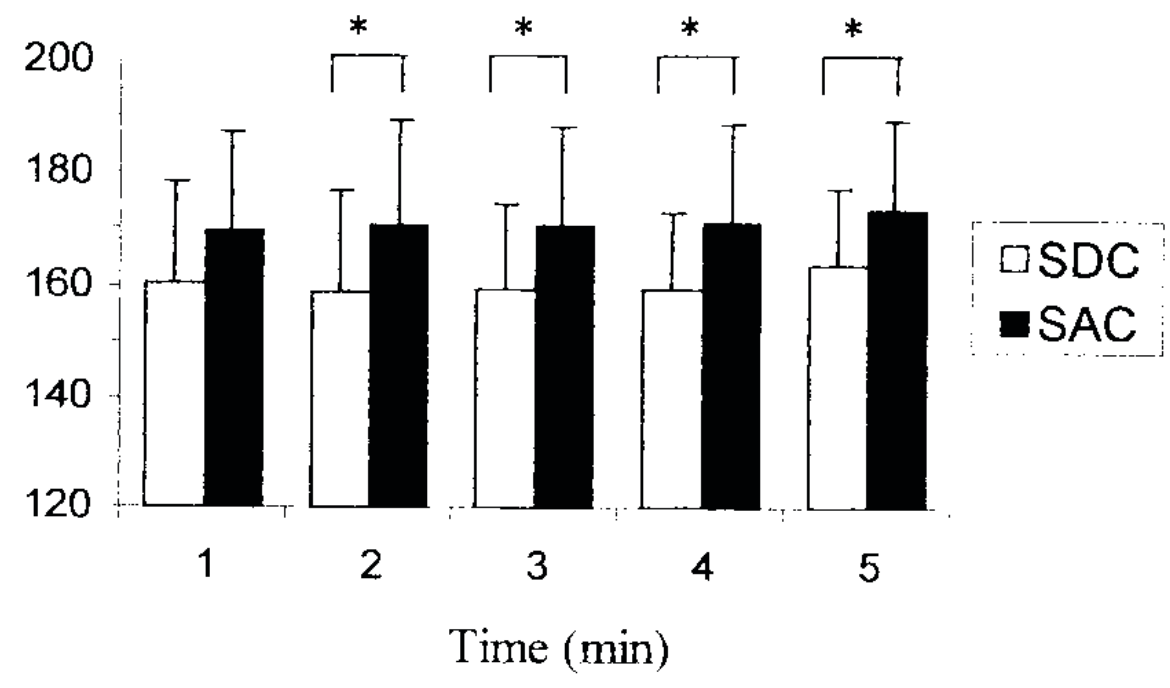


FIGURE 3-Breath-by-breath oxygen uptake responses during the cycling bouts of SAC and SDC trials in a representative subject (A) and in the subject eliminated (B). Open symbols represent SAC trial and closed symbols represent SDC trial.

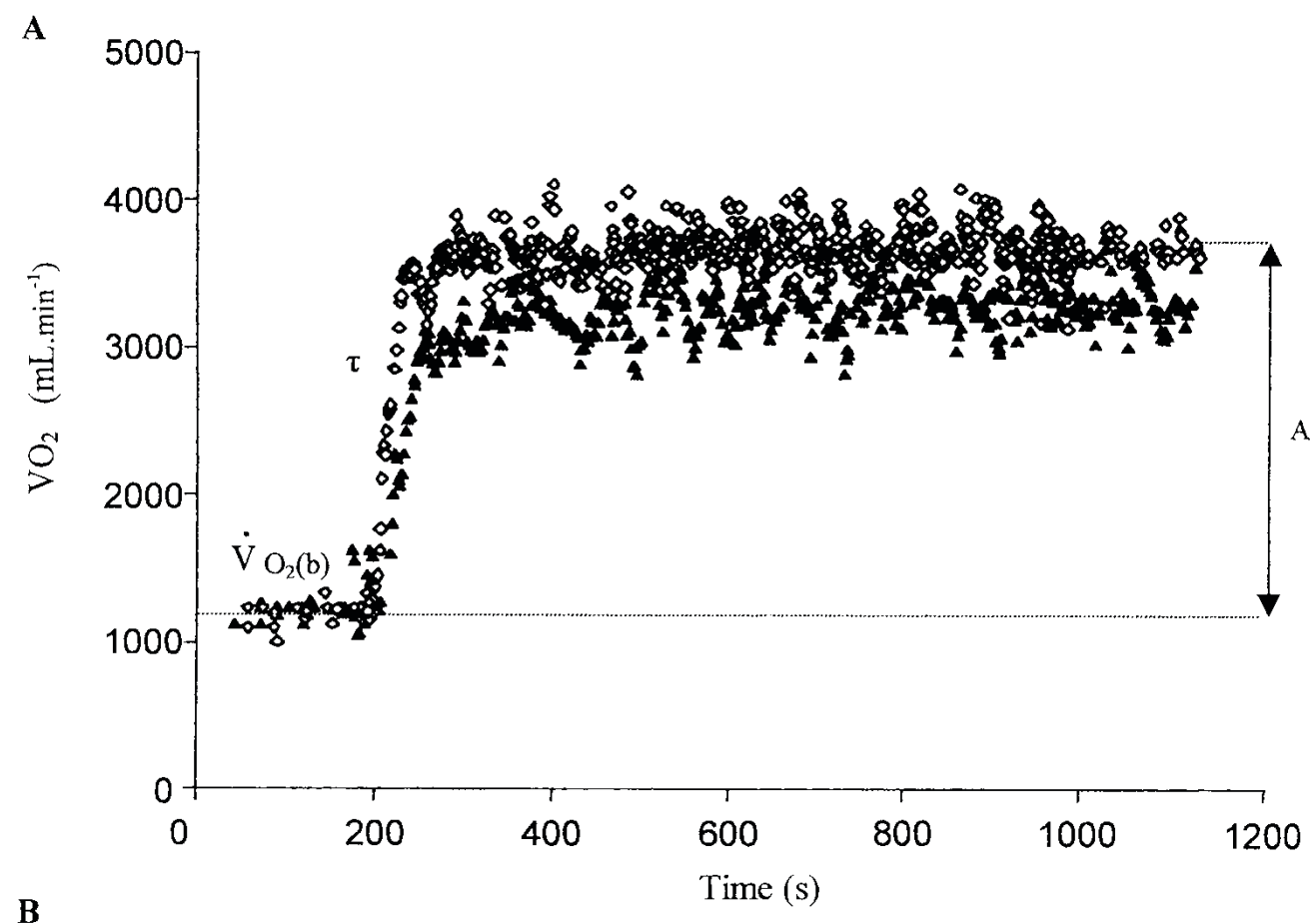

B

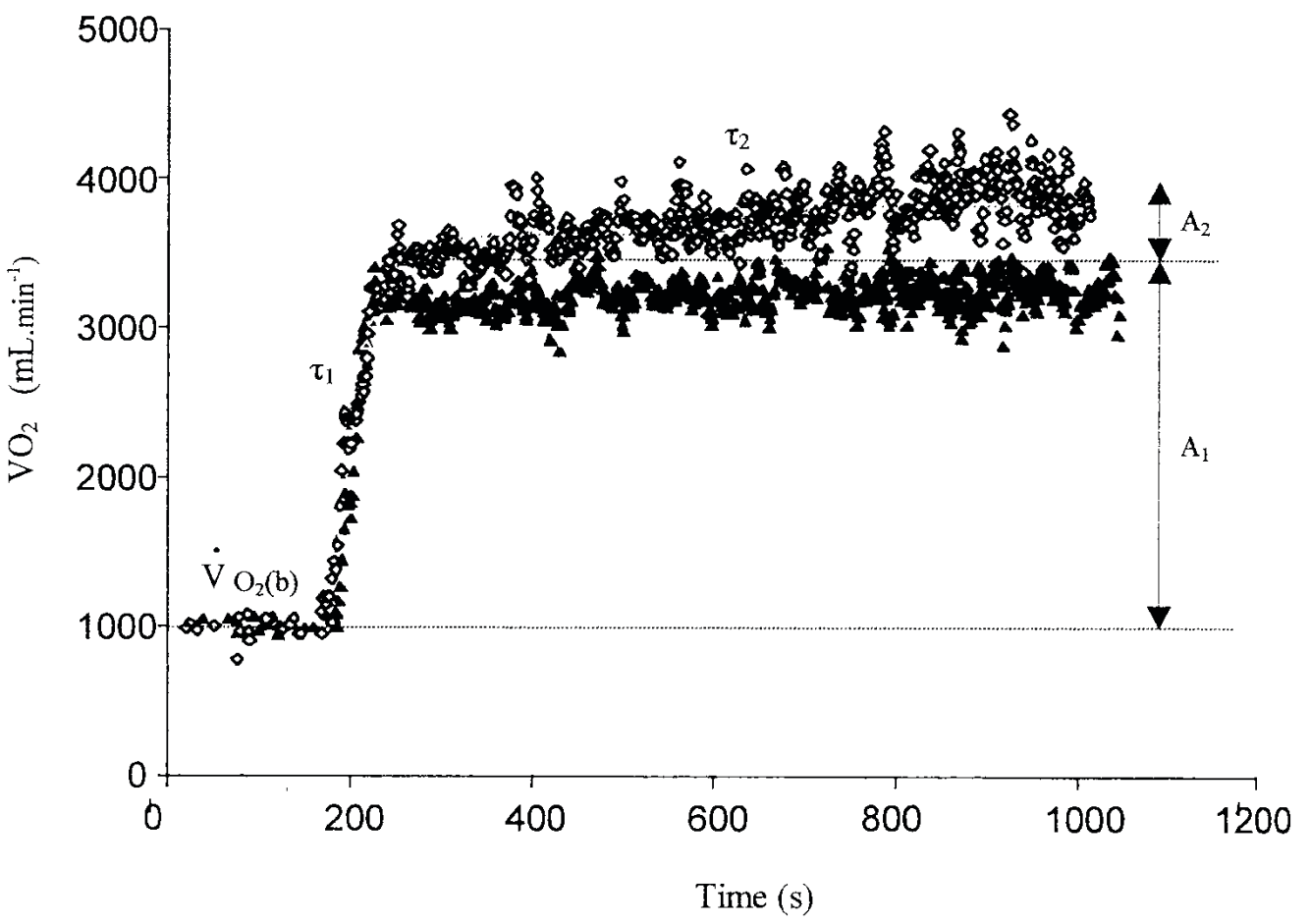


TABLE 1. Subjects' physiological characteristics during the cycling incremental test.

\begin{tabular}{|c|l|c|l|l|l|}
\hline $\begin{array}{l}\text { VO2max } \\
\left(\mathbf{m L} \cdot \mathbf{m i n}^{-}{ }^{-} \cdot \mathbf{k}^{-\mathbf{1}}\right)\end{array}$ & $\begin{array}{l}\text { MAP } \\
\mathbf{( W )}\end{array}$ & $\begin{array}{l}\mathbf{7 5 \%} \text { of MAP } \\
\mathbf{( W )}\end{array}$ & $\begin{array}{l}\text { HRmax } \\
(\mathbf{b e a t s} \cdot \mathbf{m i n}-\mathbf{1})\end{array}$ & RERmax. & $\begin{array}{l}\text { Power } \\
\text { Output } \\
\text { at } \underline{\text { VT } \mathbf{~ W})}\end{array}$ \\
\hline $66.2 \pm 6.8$ & $343 \pm 39$ & $262 \pm 29$ & $190 \pm 9$ & $1.06 \pm 0.05$ & $258 \pm 42$ \\
\hline
\end{tabular}

$\mathrm{VO}_{2 \max }$, maximal oxygen uptake; $\mathrm{MAP}$, maximal aerobic power; $\mathrm{HR}_{\max }$, maximal heart rate; $\mathrm{RER}_{\max }$, maximal respiratory exchange ratio; power output at VT, power output corresponding to the ventilatory threshold.

Table 2. Effect of drafting during prior swimming on mean values of physiological parameters and pedal rate recorded during subsequent cycling exercice.

\begin{tabular}{|l|c|c|}
\hline & & \\
& SDC & SA \\
& & \\
\hline $\mathrm{VO}_{2}\left(\mathrm{~mL} \cdot \mathrm{min}^{-1}\right)$ & & $4003 \pm 469^{*}$ \\
\hline $\mathrm{LA}\left(\mathrm{mmol} \cdot \mathrm{L}^{-1}\right) 3 \mathrm{~min}$ & $3827 \pm 494$ & $7.4 \pm 2.2^{*}$ \\
& $6.3 \pm 2.0$ & $7.7 \pm 2.9^{*}$ \\
\hline $\mathrm{GE}(\mathrm{h})$ & $6.4 \pm 2.5$ & $18.6 \pm 0.7^{*}$ \\
\hline $\mathrm{HR}\left(\right.$ beats $\left.\bullet \mathrm{min}^{-1}\right)$ & $19.5 \pm 1.5$ & $177 \pm 13^{*}$ \\
\hline $\mathrm{VE}\left(\mathrm{L} \cdot \mathrm{min}^{-1}\right)$ & $171 \pm 13$ & $113.5 \pm 10.4$ \\
\hline $\mathrm{RF}\left(\mathrm{cycles} \cdot \mathrm{min}^{-1}\right)$ & $106.0 \pm 16.7$ & $43.7 \pm 6.1$ \\
\hline Pedal rate $\left(\mathrm{rev} \cdot \mathrm{min}^{-1}\right)$ & $39.6 \pm 6.2$ & $91.1 \pm 7.7^{*}$ \\
\hline
\end{tabular}

$\mathrm{VO}_{2}$, oxygen uptake; LA, blood lactate concentration; GE, gross efficiency; HR, heart rate; VE, expiratory flow; $\mathrm{RF}$, respiratory frequency.

* Significant difference between SAC and SDC trials; $P<0.05$. 